\title{
REPORTS
}

\section{Report of the IOI Workshop "Creating an International Informatics Curriculum for Primary and High School Education"}

\author{
Nevena ACKOVSKA ${ }^{1}$, Ágnes ERDÖSNÉ NÉMETH ${ }^{2}$, \\ Emil STANKOV ${ }^{1}$, Mile JOVANOV ${ }^{1}$ \\ ${ }^{1}$ Faculty of Computer Science and Engineering, University Ss. Cyril and Methodius \\ st. Rugjer Boshkovikj 16 Skopje, Macedonia \\ ${ }^{2}$ ELTE IK, Budapest \\ Batthyány Lajos Gimnázium, Nagykanizsa \\ e-mail:nevena.ackovska@finki.ukim.mk,agi@microprof.hu \\ emil.stankov@gmail.com,mile.jovanov@gmail.com
}

\begin{abstract}
This report entangles the endeavors undertaken during the IOI Workshop "Creating an International Informatics Curriculum for Primary and High School Education". Considering the need to discuss the role of informatics in the primary and secondary education, the Workshop participants tried to encapsulate several activities that might give insight on how to treat this issue with success. An overview of the current situation with the informatics education in thirteen countries was presented. Further, a group work took place considering relevant topics in creating informatics curricula and computational thinking. A fruitful discussion that considered establishing guidelines and further steps in creating informatics curricula and some ways to promote informatics concluded the Workshop.
\end{abstract}

Keywords. informatics curriculum, promoting informatics.

\section{Introduction}

The IOI Workshop "Creating an International Informatics Curriculum for Primary and High School Education” took place from 19-24.04.2015 in Bitola, Macedonia. It gath- 
ered 16 people coming from the following countries: Belgium, Brazil, Bulgaria, Croatia, Estonia, Hungary, Lithuania, Macedonia, Serbia and Slovenia. It also included 2 Skype presentations coming from New Zealand and Bolivia, and a submission coming from India. There were three different sets of activities that took place on this Workshop:

1) Country presentations, including tutorials on Tools used in some of the countries.

2) Workgroup activities.

3) Conclusions, results, recommendations and further steps that should be taken.

In the sequel of this document an elaboration on all of the activities is presented. The next chapter gives an overview of the details of the primary and the secondary school curricula in the countries whose representatives presented on this IOI Workshop. The effort done in four different workgroups considering relevant topics in creating informatics curricula and computational thinking is presented in chapter three. The recommendations, conclusions and the possible further steps are given at the end of this report.

\section{Participating Countries' Specifics}

During the IOI Workshop each country representative presented the specifics of the primary and the secondary school curricula in his own country. Some of the characteristics and best practices that each country presented from their specific experience in informatics education are given in the sequel:

- Belgium: Neither Informatics nor ICT is in the official curriculum in Belgium. Some efforts are made through informal teaching: 1) Encourage participation to first stages of contests (IOI, Bebras...) for everyone, making them easier. 2) Organise workshops and fairs to promote informatics at large.

- Bolivia: There is not enough staff for teaching Competitive Programming; however there is a community of ICPC contestants that helps the school students in order to prepare for national and international contests. There isn't any standard about CS in schools, but the schools start to use as a standard the Syllabus of IOI Bolivia which is used for the local contests.

The most known and used path is the syllabus that starts from 10 years old children (or 5th of primary) and is divided in 4 level of contests (Level 0: Operating Systems (Windows and Linux), Level 1: Introduction to Programming with videogames (Scratch, Kodu or other), Level 2: Basic Programming (until Arrays), Level 3: Advanced Programming (Data Structures including Graphs)).

- Brazil: In Brazil there is no ICT or Programming in the official curriculum, except at Professional Education Courses. A new program started, but only in a few schools, to include Informatics as "complementary activities" at Primary and Secondary levels, involving only Digital Literacy and ICT.

- Bulgaria: There are two curricula in parallel: IT curriculum (Computer system, Organization of data and information carriers, Image processing...) and Informatics curriculum (Math foundation - binary system, propositional logic, formal lan- 
guages, computer architecture, operating system, introduction to algorithms and data structures, programming). Most of the regular schools have no teachers in Informatics and do not really teach Informatics.

- Croatia: Informatics in primary schools is an elective subject, attended only by a small number of pupils. The teaching plan consists of basics of using the computer, using Office applications and principles of programming. Because of the enthusiasm of the teachers, there are groups where something more on programming can be learned. In secondary schools, informatics is mandatory but in most of the schools only for one year. Only in math-science gymnasiums, the programming and teaching of logical thinking are present through all four years. Preparing for programming competitions is part of additional elective informatics. In the creation of the new curriculum that has started recently, there is a plan to have informatics as mandatory subject in primary schools.

- Estonia: Some of the recommendations are: 1) Teachers should have some freedom in the curriculum to have the option to choose what and how they want to teach; 2) Various learning and teaching materials should be created systematically and made publicly available online for free; 3 ) Constant teacher trainings should be provided to keep teachers aware of the currently most suitable software for these activities and able to search for suitable tools; 4) Informatics should be viewed as an independent scientific subject including elements of programming; 5) Society (pupils, teachers, parents, municipality, stakeholders, researchers, etc.) should be included in raising the awareness of the importance of informatics; 6) Extra curriculum activities and competitions should be supported to increase the motivation of pupils learning IT.

- Hungary: 1) It is very late to teach the fundamentals of informatics as a science in secondary school, it is a must to begin it in an early primaries; 2) Informatics means Information and Communication Technology (ICT), Computer Science (CS) and Digital Literacy (DL), altogether.

- India: Due to the lack of infrastructural facilities like electricity $(43 \%)$, broadband connectivity, computers (76\%), and qualified teachers, the teaching of computer programming is currently restricted to urban cities and towns of India.

- Lithuania: 1) Learning by contests (introducing Bebras tasks); 2) Involving various players in informatics education: pupils, teachers, parents, municipality, stakeholders, researchers...) creating resources for teaching and learning informatics available to everybody (description of methods, exercises, learning objects...).

- Macedonia: 1) Introducing programming in primary school as an elective subject in one of the last two years of study; 2) Most of the topics covered in the informatics courses are related to programming; 3 ) Intention to introduce programming and algorithmic thinking starting from the first grade, and also in the lower grades as a part of the other subjects; 4) Most of the pupils interested in programming are attracted through the competitions.

- New Zealand: There is no compulsory Computational Thinking or Computer Science in years 1 to 10 . In years 11 to 13 there have been elective standards in Programming and Computer Science, phased in since 2011. So far numbers are 
small. Teachers have lacked Ministry funded professional development to learn Programming although there has been support for "the big ideas" of Computer Science through CS4HS workshops and a student and teacher website. School and parental awareness of the need for CT in the curriculum at all year levels is slowly gathering strength.

- Serbia: In the elementary school there are elective IT courses in grades 5 and 6 (36hrs), oriented to computer use (including modeling with Scratch), and also in grades 7 and 8 (34hrs). Plus additional hours of ICT are "integrated into other disciplines". In Gymnasiums, informatics is taught with one or two classes per week, which is really low compared to other important courses. The aim of the course is the acquisition of basic computing literacy and training students to use computers in their further education and work. Unfortunately, the emphasis is far from the algorithmic nature.

- Slovenia: The informatics curriculum in Slovenia is on a satisfactory level in the first few years (primary school), where students have the option to learn the basics of algorithmic thinking and programming, but it declines rapidly from then on. Currently, informatics is mandatory only in the secondary schools, where only 70 hours are assigned. A big problem is the lack of qualified teachers, which is (probably) due to low salaries and the lack of interest for the profession. "Best" practices: Competitions are excellent for attracting young pupils into the field and they motivate them to refine their skills. Due to the currently minuscule curriculum, the best competitors think they already learned everything and very often decide to continue their university studies in some other field.

\section{Work Group Reports}

Additional work has been done in 4 work groups. The specifics of the analyses done by every workgroup are given below.

\subsection{Methodology of Creating an International School Curriculum for Informatics and Information Technologies (ISCIIT)}

This group's first objective was to study the available curricula for computer science and informatics technologies for undergraduate students. The recommendations from IEEE and ACM were overviewed, as well as the learning standards recommended by the Computer Science Teachers Association, Computing at School Working Group and the Australian Curriculum. The main goal was to provide a set of recommendations for the creation of programs for informatics in primary and secondary schools.

The Curriculum Guidelines should identify a body of knowledge, set of learning outcomes, core and curriculum models. The body of knowledge needs to be organized by knowledge areas that are broken down into units. Each unit is further subdivided into a set of topics. The age when a set of topics should be introduced must be specified. 


\subsection{Analysis of the Joint Report from Informatics Europe and ACM Europe}

The report analyzed by this group was developed by a group of experts from academia and industry representing the two principal scientific societies in the field, Informatics Europe and ACM Europe. More resources: (Barr and Stephenson, 2011), (Delors, 1996), (Kingfield, 2012), (Snyder, 1999), (Snyder, 2005).

Based on the analysis of the current situation and of experiences in many countries across Europe, this report makes four key recommendations:

- All students should benefit from education in digital literacy, starting from an early age and mastering the basic concepts by the age of 12 . Digital literacy education should emphasize not only skills, but also the principles and practices of using them effectively and ethically.

- All students should benefit from education in informatics as an independent scientific subject, studied both for its intrinsic intellectual and educational value and for its applications to other disciplines.

- A large-scale teacher training program should urgently be started. To bootstrap the process in the short term, creative solutions should be developed involving school teachers paired with experts from academia and industry.

- The definition of informatics curricula should rely on the considerable body of existing work on the topic and the specific recommendations of the present report.

\subsection{Computational Thinking}

One of the main goals for computer science should be to teach computational thinking, just as the mathematics' main goal is to teach logical thinking and to increase problem solving skills. This should be achieved by incorporating the concepts of computational thinking into most/all courses as the implementation of these concepts is interdisciplinary. The process can benefit from computer scientists, who can promote understanding of how to bring computational processes to bear on problems in other fields. Also this can help students understand processes as algorithmic. In addition to incorporating these skills formally in the classroom, research regarding the implementation of computational thinking skills in informal education also provides valuable insights.

However, embedding computational thinking in primary and secondary education requires a practical approach, for example:

- What would computational thinking look like in the classroom?

- What are the skills that students would demonstrate?

- What would a teacher need in order to put computational thinking into practice?

- What are teachers already doing that could be modified and extended?

More resources: (Barr and Stephenson, 2011), (Brennan and Resnick, 2012), (Lee et al., 2011), (Mannila et al., 2014), (Wing, 2006), (Wing, 2011). 


\subsection{Preparing a Template for Gathering Data for a Catalogue of Experiences}

The purpose of this sub-group was to provide a process and a framework for producing a "Catalogue of Existing Experiences" in Informatics and Computer Science at Schools, in different countries.

Some documents have been reviewed, such as (Guerra et al., 2012).

After some discussion it was decided that the best way to produce such a catalogue was to use the IOI community as an input, preparing a questionnaire to be sent to IOI leaders and deputy leaders. It was decided that the questionnaire should be divided into two sections: one with more general information (for example, about the organization of education and of schools), and one with more specific information (for example, which topics are taught at each grade).

The agreement has been made to prepare a questionnaire which should be disseminated to 5-10 valuable teachers in IOI participating countries. It is expected that this questionnaire will gather valuable data that will be used as a basis for building future informatics curricula.

\section{Conclusions and Recommendations}

The activities that took place in the IOI Workshop "Creating an International Informatics Curriculum for Primary and High School Education" lead to several conclusions and recommendations. They are sublimated below:

1. Primary and secondary levels of education (ages 6 through 19) need to incorporate informatics. As the experience in many European countries has shown, pupils by the age of 12 can be educated, and the education must cover the technical usage of IT tools as well as the rules on how to use them safely, effectively and ethically.

2. Informatics should become a mandatory subject in schools.

3. Combining formal and informal education should be supported.

4. Various methods of teaching and learning informatics fundamentals should be used at primary school: tools that use visual block based programming, learning through games, game creation, robotics, CS unplugged etc.

5. For advanced informatics curricula, modular design is highly recommended.

6. Informatics ought to be thought by teachers trained in informatics.

7. Constant teacher training should be carried out due to the constant changes in the field of informatics.

8. Country specifics should be considered when developing informatics curriculum.

\section{Acknowledgement}

The authors would like to express their sincere gratitude to all the participants of the IOI Workshop 2015, for the hard work done and the efforts made in order to define 
sound directions and construct a proposal that the IOI community could use for the purpose of establishment of an international informatics curriculum for primary and secondary school education. Here the full list of participants is presented: Sébastien Combéfis - Belgium, Willmar Pimentel - Bolivia, Ricardo Anido - Brazil, Krassimir Manev - Bulgaria, Krešimir Malnar - Croatia, Maria Gaiduk and Tauno Palts - Estonia, Ágnes Erdősné Németh - Hungary, Narayen Ugar - India, Valentina Dagienė - Lithuania, Mile Jovanov, Emil Stankov, Marija Mihova, Nevena Ackovska and Bojan Kostadinov - Macedonia, Margot Phillipps - New Zeland, Jelena Hadzi-Puric - Serbia, and Darko Pevec - Slovenia.

\section{References}

Barr, V., Stephenson, C. (2011). Bringing computational thinking to K-12: what is involved and what is the role of the computer science education community? ACM Inroads, 2(1), 48-54.

http://dl.acm.org/citation.cfm?id=1929905

Bebras - International Contest on Informatics and Computer Fluency (2007-2015). http : / / bebras . org

Brennan, K., Resnick, M. (2012). New frameworks for studying and assessing the development of computational thinking. In: Proceedings of the 2012 annual meeting of the American Educational Research Association. Vancouver, Canada.

http://web.media.mit.edu/ kbrennan/files/Brennan_Resnick_AERA2012_CT.pdf

CECE - Committee on European Computing Education (2013-2015).

http: / / www . uni-muenster.de/CECE/

Delors, J. (1996). Learning: the Treasure Within, Report to UNESCO of the International Commission on Education for the Twenty-first Century. UNESCO publishing. http: / / www . unesco.org/delors/

Exploring Computational Thinking. https://www.google.com/edu/resources/programs/exploring-computational-thinking/

Guerra, V., Kuhnt, B., Blöchliger, I. (2012). Informatics at School - Worldwide: An International Exploratory Study about Informatics as a Subject at Different School Levels. http://fit-in-it.ch/sites/default/files/small box/study informatics at school _ worldwide.pdf

Informatics Education: Europe Cannot Afford to Miss the Boat (2013). Report of the joint Informatics Europe \& ACM Europe Working Group on Informatics Education.

http://europe.acm.org/iereport/ACMandIEreport.pdf

ISTE Computational Thinking for All. http: //www. iste.org/learn/computational-thinking

Kingfield, N. (2012). Fostering tech talent in schools. New York Times, 30 September 2012. http: //nyti.ms/Sudld4

Lee, I., Martin, F., Denner, J., Coulter, B., Allan, W., Erickson, J., Malyn-Smith, J., Werner, L. (2011). Computational thinking for youth in practice. ACM Inroads, 2(1), 32-37.

http://dl.acm.org/citation.cfm?id=1929902

Mannila, L., Dagiené, V., Demo, B., Grgurina, N., Mirolo, C., Rolandsson, L., Settle, A. (2014). Computational thinking in K-9 education. In: Proceedings of the Working Group Reports of the 2014 on Innovation \& Technology in Computer Science Education Conference (ITiCSE-WGR '14). 1-29.

http://dl.acm.org/citation.cfm?id=2713610

Snyder, L. (1999). Being Fluent with Information Technology. Washington, D.C., The National Academies Press (NAP) http: / / www . nap.edu/openbook.php? record_id=6482 \&page=1

Snyder, L. (2005). Bringing fluency with information technology to high schools. CSTA Voice, 1(3). http: / / bit.1y/cCPUFR

Royal Society (2012). Shut Down or Restart? The Way Forward for Computing in UK Schools. January 2012. http://bit.ly/zDqu7F

Wing, J.M. (2006). Computational thinking. Communications of the ACM, 49(3), 33-35. https://www.cs.cmu.edu/ 15110-s13/Wing06-ct.pdf

Wing, J.M. (2011). Computational Thinking: What and Why. http://www.cs.cmu.edu/link/researchnotebook-computational-thinking-what-and-why 


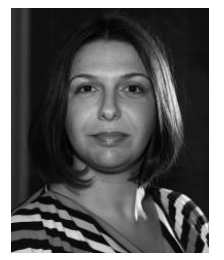

N. Ackovska holds B.Sc. in Computer Engineering, Informatics and Automation (2000), M.Sc. in Intelligent Systems (2003), and Ph.D. in the field of Intelligent Systems (2008) from "Sts. Cyril and Methodius University" in Skopje, Macedonia. She is Associate Professor at the Faculty of Computer Science and Engineering at UKIM. She is author of five books (in Macedonian) and more than 60 research articles in the field of Intelligent Systems and hardware education. Her research interest are Beings, both living and artificial. Dr. Ackovska is a member of the Computer Society of Macedonia. She has actively participated in the organization and realization of the Macedonian national competitions and Olympiads in informatics since 2001.

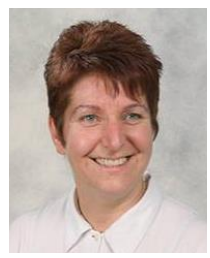

Á. Erdősné Németh teaches mathematics and informatics at Batthyány Lajos High School in Nagykanizsa. A lot of her students are in the final rounds of the national informatics tournaments. She is a Ph.D. student in the Doctoral School of Faculty of Informatics at the University of Eötvös Loránd in Budapest. Her current research interest is teaching computer science for talented pupils.

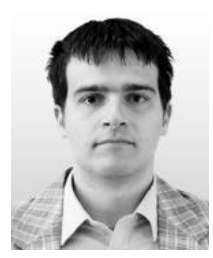

E. Stankov is a teaching and research assistant at the Faculty of Computer Science and Engineering, University "Ss. Cyril and Methodius", in Skopje. He is a member of the Executive Board of the Computer Society of Macedonia, and has actively participated in the organization and realization of the Macedonian national competitions and Olympiads in informatics since 2009. Currently he is a Ph.D. student at the Faculty of Computer Science and Engineering. His research includes analysis of program code correctness using different techniques, and its application to e-learning.

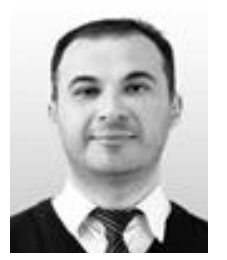

M. Jovanov is an assistant professor at the Faculty of Computer Science and Engineering, University "Ss. Cyril and Methodius", in Skopje. As the President of the Computer Society of Macedonia, he has actively participated in the organization and realization of the Macedonian national competitions and Olympiads in informatics since 2001. He has been a team leader for the Macedonian team at International Olympiads in Informatics since 2006. His research interests include development of new algorithms, future web, and e-education, and he has authored more than 40 research peer reviewed papers. 